\title{
THE PAST AND FUTURE OF THE AHP IN HEALTH CARE DECISION MAKING
}

\author{
Marjan Hummel* \\ Dept. of Health Technology \& Services Research \\ University of Twente \\ Enschede, The Netherlands \\ E-mail: j.m.hummel@utwente.nl \\ Maarten IJzerman \\ Dept. of Health Technology \& Services Research \\ University of Twente \\ Enschede, The Netherlands \\ E-mail: m.j.ijzerman@utwente.nl
}

\begin{abstract}
Objective. Health care decision making is a complex process involving many stakeholders and allowing for multiple decision criteria. The Analytic Hierarchy process (AHP) can support these complex decisions that relate to the application and coverage of health care technologies. The objective of this study is to review the past applications of the AHP in supporting health care decision making, and to make recommendations for its future use.

Method. We conducted a systematic review of AHP applications in health care, as described in the relevant medical, health-economical, psycho-sociological, managerial, and applied mathematical literature.

Results. We found 62 distinctive AHP applications in health care. Of the retrieved applications, $13 \%$ focus on shared decision-making between patient and clinician, $27 \%$ on the development of clinical practice guidelines, $5 \%$ on the development of medical devices and pharmaceuticals, $40 \%$ on management decisions in health care organizations, and $15 \%$ on the development of national health care policy.

Conclusions. From the review it is concluded that the AHP is suitable to apply in case of complex health care decision problems, a need to improve decision making in stead of explain decision outcomes, a need to share information among experts or between clinicians and patients, and in case of a limited availability of informed respondents. We foresee the increased use of the AHP in health economical assessment of technology.
\end{abstract}

Keywords: Analytic Hierarchy Process, systematic literature review, health care decision making, health technology assessment.

\section{Introduction}

Patients and society poses high and diverse demands on health care interventions. The demands relate to medical and economical, social, legal, ethical, organizational or technical criteria. Established methods used in Health Technology Assessment or HTA can be roughly divided into clinical trials and economic studies. Clinical trials investigate the clinical outcome of health care interventions and build the evidence based medicine library. Clinical outcomes include for example mortality and morbidity. Economic

\footnotetext{
* Corresponding author
} 
evaluations, such as cost-effectiveness or cost-utility analyses, incorporate a broader range of outcome measures, such as quality-adjusted life years and willingness to pay, relative to the additional resources required for that particular intervention. All methods have in common that they are used to inform healthcare decision makers about the coverage and application of health care interventions. The process of health care decision making is, however, not only dependent on clinical and economic performance. It is a complex and multi-factorial process involving many stakeholders and allowing for different opinions.

Multi-criteria decision analysis (MCDA) can be used to support these complex and multifaceted decisions. They help decision-makers to evaluate a finite number of alternative health care interventions under a finite number of performance criteria. One validated technique for MCDA is Saaty's Analytic Hierarchy Process (AHP) (Saaty, 1994). Other commonly used tools for multi-criteria or multi-attribute decision analys is in health care are the elimination and choice translating reality (ELECTRE), the simple multi-attribute rating technique (SMART), multi-attribute utility theory (MAUT), and conjoint analysis. Experimental comparisons have been made and concluded that each of the MCDA methods has its own advantages and disadvantages. For example, in two studies comparing AHP and conjoint analys is it was concluded that AHP has clear advantages in case of complex decisions (Mulye, et al, 1998; Scholl, et al, 2005). Although much of the work on AHP has been done outside the healthcare sector, some empirical applications suggest that the AHP can be an effective tool to support health care decision making about the coverage and application of health care interventions (Dolan \& Bordley, 1993; Hummel, et al., 1995).

\section{Objective}

The objective of this study is to review the past use of the AHP in health care decision making. Based on the review we aim to provide suggestions on the future use of the AHP in health care decision making and on its use for health economic evaluation of new technology in particular.

\section{Methods}

We conducted a systematic literature review on the use of the Analytic Hierarchy Process (AHP) in health care. Within de English language databases of Pub Med and Web of Science we searched in the abstracts for the keywords "Analytic Hierarchy Process" AND ("patient" OR "patients" OR "health" OR "healthcare" OR "medical" OR "clinical" OR "hospital"). All retrieved abstracts were screened to include only those articles that were actually focusing on the AHP methodology and on applications within health care. We then summarized the evidence on best practices regarding the decision tasks, patient-relevant criteria to include in these tasks, and characteristics of the AHP participants.

\section{Results}

We found 93 articles focusing on the use of the AHP in health care. In order to arrange the 62 distinctive AHP applications found, we distinguished among five decision task levels. Of the retrieved applications, $13 \%$ focus on shared decision-making between patient and clinician, $27 \%$ on the development of clinical guidelines, $5 \%$ on the development of health care innovations, $40 \%$ on management decisions in health care organizations, and $15 \%$ on the development of national health care policy. Table 1, 2, 3, 4 and 5 describe the AHP applications in these decision areas. 
Table 1. Shared decision making

\begin{tabular}{|l|c|c|c|l|l|l|}
\hline Author & Year & \# crit. & \# alt. & $\begin{array}{l}\text { Individual } \\
\text { or group }\end{array}$ & Participants & $\begin{array}{l}\text { Pairwise comparisons } \\
\text { or direct rating }\end{array}$ \\
\hline $\begin{array}{l}\text { Shared decision } \\
\text { making: }\end{array}$ & 2002 & 7 & 6 & individual & $\begin{array}{l}46 \text { patients } \\
\text { focus group }\end{array}$ & $\begin{array}{l}\text { pairwise comparisons } \\
\text { Dolan }\end{array}$ \\
\hline Liberatore & 2003 & 12 & 3 & $\begin{array}{l}\text { group } \\
\text { individual }\end{array}$ & $\begin{array}{l}\text { patients } \\
\text { pairwise comparisons }\end{array}$ \\
\hline Richman & 2005 & 9 & 8 & individual & 12 clinicians & pairwise comparisons \\
\hline Hummel & 2005 & 5 & 2 & individual & 34 patients & pairwise comparisons \\
\hline Katsumura & 2008 & 13 & 2 & individual & 353 patients & pairwise comparisons \\
\hline Van Til & 2008 & 4 & 2 & individual & 17 patients & pairwise comparisons \\
\hline IJzerman & 2009 & 6 & 5 & individual & 142 patients & pairwise comparisons \\
\hline Kitamura & 2010 & 5 & 2 & individual & 31 patients & pairwise comparisons \\
\hline
\end{tabular}

In case of shared decision making, this review shows that individual patients can be supported to weight the diverse subjective and objective decision criteria. Most commonly, the amount of criteria range from 5 to 10 decision criteria. The outcomes only represent the preferred choice for the specific patient involved.

Table 2. Development of clinical guidelines

\begin{tabular}{|c|c|c|c|c|c|c|}
\hline Author & Year & \# crit. & \# alt. & $\begin{array}{l}\text { Individual } \\
\text { or group }\end{array}$ & Participants & $\begin{array}{l}\text { Pairwise comparisons } \\
\text { or direct rating }\end{array}$ \\
\hline \multicolumn{7}{|c|}{ Diagnosis: } \\
\hline Cook & 1990 & 9 & 12 & group & clinicians & direct rating \\
\hline Dolan & 1993 & 5 & 4 & individual & $\begin{array}{l}25 \text { patients, } \\
22 \text { clinicians }\end{array}$ & pairwise comparisons \\
\hline Castro & 1996 & 4 & 4 & individual & 6 clinicians & pairwise comparisons \\
\hline Saaty & 1998 & 11 & 2 & individual & clinician & pairwise comparisons \\
\hline Koch & $\begin{array}{l}1998 \\
- \\
2000\end{array}$ & 33 & - & 4 groups & $\begin{array}{l}\text { health prof., } \\
\text { relatives patients, } \\
\text { citizens }\end{array}$ & direct rating \\
\hline Barosi & 2007 & & - & $\begin{array}{l}\text { Individual and } \\
\text { group }\end{array}$ & - & $\begin{array}{l}\text { pairwise comparisons } \\
\text { pairwise comparisons }\end{array}$ \\
\hline Uzoka & 2011 & 22 & 5 & individual & 6 clinicians & direct rating \\
\hline Pecchia & epub & 35 & - & individual & 191 health prof. & pairwise comparisons \\
\hline \multicolumn{7}{|c|}{ Treatment: } \\
\hline $\begin{array}{l}\text { Peralta } \\
\text { Carcelen }\end{array}$ & 1997 & 5 & 2 & individual & $\begin{array}{l}92 \text { patients, } \\
80 \text { health prof. }\end{array}$ & $\begin{array}{l}\text { pairwise comparisons } \\
\text { pairwise comparisons }\end{array}$ \\
\hline Dolan & 1998 & 9 & 7 & individual & 61 clinicians & pairwise comparisons \\
\hline Carter & 1999 & 14 & 5 & individual & 2 clinicians & pairwise comparisons \\
\hline Kuntz & 1999 & 798 & 2 & $\begin{array}{l}\text { Individual and } \\
\text { group }\end{array}$ & 9 clinicians & pairwise comparisons \\
\hline Hummel & 2005 & 24 & 2 & group & 7 health prof., patient & pairwise comparisons \\
\hline Singh & 2006 & 10 & 4 & - & - & direct rating \\
\hline Van Til & 2008 & 17 & 6 & group & 10 health prof. & pairwise comparisons \\
\hline Sharma & 2011 & 13 & 2 & individual & 96 patients & pairwise comparisons \\
\hline \multicolumn{7}{|c|}{ Clinical performance measurement: } \\
\hline Kunene & 2005 & 9 & - & - & - & direct rating \\
\hline
\end{tabular}


In case of clinical guidelines, individual clinicians and, if relevant, patients individually compare the relative importance's of the decision criteria. In case of new technology, the importance of the criteria can be assessed in a multidisciplinary group session. The criteria analysed commonly range from 10 to 15 decision criteria.

Table 3. Biomedical innovation

\begin{tabular}{|c|c|c|c|c|c|c|}
\hline Author & Year & \# crit. & \# alt. & $\begin{array}{l}\text { Individual } \\
\text { or group }\end{array}$ & Participants & $\begin{array}{l}\text { Pairwise comparisons } \\
\text { or direct rating }\end{array}$ \\
\hline \multicolumn{7}{|c|}{ Technology development: } \\
\hline Hummel & 2000 & 19 & 3 & group & 9 health prof., engineers & pairwise comparisons \\
\hline Hummel & 2000 & 24 & 3 & group & $\begin{array}{l}8 \text { health prof., engineers, } \\
\text { patient }\end{array}$ & pairwise comparisons \\
\hline $\begin{array}{l}\text { Van der } \\
\text { Wetering }\end{array}$ & 2008 & 14 & 5 & individual & $\begin{array}{l}6 \text { health prof., engineers, } \\
\text { patient, policy makers }\end{array}$ & pairwise comparisons \\
\hline
\end{tabular}

In case of early technology assessment, 15 to 25 decision criteria are assessed in a multidisciplinary group composed of clinicians, biomedical engineers and if relevant patients. The outcomes are meant to represent a specific group of patients.

Table 4. Health care management

\begin{tabular}{|c|c|c|c|c|c|c|}
\hline Author & Year & \# crit. & \# alt. & $\begin{array}{l}\text { Individual } \\
\text { or group }\end{array}$ & Participants & $\begin{array}{l}\text { Pairwise comparisons } \\
\text { or direct rating }\end{array}$ \\
\hline \multicolumn{7}{|c|}{ Equipment procurement: } \\
\hline Sloane & $\begin{array}{l}2003 \\
2004\end{array}$ & 23 & 3 & individual & $\begin{array}{l}1 \text { manager, } \\
1 \text { clin. engineer }\end{array}$ & pairwise comparisons \\
\hline Balestra & 2007 & 32 & - & individual & 2 clinicians & pairwise comparisons \\
\hline Wu & 2007 & 24 & 3 & individual & $\begin{array}{l}13 \text { administrators, } \\
\text { researchers }\end{array}$ & pairwise comparisons \\
\hline Baykasoglu & 2009 & 10 & 2 & group & 10 managers, clinicians & pairwise comparisons \\
\hline \multicolumn{7}{|c|}{ Contractor selection: } \\
\hline Turri & 1988 & 7 & 3 & group & hospital committee & pairwise comparisons \\
\hline Hsu & 2008 & 22 & 4 & Individual & 6 hospital ad ministrators & pairwise comparisons \\
\hline \multicolumn{7}{|c|}{ Performance measurement of services: } \\
\hline Bilsel & 1996 & 24 & 9 & individual & clients & pairwise comparisons \\
\hline Longo & 2002 & 11 & 8 & Individual & $\begin{array}{l}\text { nurses, clinicians and } \\
\text { researchers }\end{array}$ & pairwise comparisons \\
\hline Hariharan & 2005 & 22 & 3 & individual & clinicians, managers & direct rating \\
\hline Dey & 2006 & 25 & 3 & 6 groups & clinicians, managers & pairwise comparisons \\
\hline Chang & 2006 & 40 & - & individual & 30 clients & pairwise comparisons \\
\hline Hsu & 2009 & 17 & - & individual & 303 patients & pairwise comparisons \\
\hline Ajami & epub & 44 & 3 & individual & researchers & pairwise comparisons \\
\hline \multicolumn{7}{|c|}{ Appropriation of support services: } \\
\hline Lee & 1999 & 6 & 9 & individual & system experts & direct rating \\
\hline Rossetti & 2001 & 18 & 2 & individual & director & direct rating \\
\hline Da Rocha & 2005 & 4 & 2 & - & - & direct rating \\
\hline \multicolumn{7}{|c|}{ Strategic marketing: } \\
\hline Javalgi & 1991 & 9 & 3 & group & $\begin{array}{l}\text { managers, clinicians, } \\
\text { patients }\end{array}$ & pairwise comparisons \\
\hline
\end{tabular}




\begin{tabular}{|c|c|c|c|c|c|c|}
\hline Sinuany-Stern & 1995 & 5 & 6 & individual & 11 experts & direct rating \\
\hline Wu & 2005 & 24 & 3 & individual & 13 administrators & pairwise comparisons \\
\hline Tzung & 2007 & 23 & 3 & individual & 207 patients & pairwise comparisons \\
\hline Ohta & 2007 & 5 & 9 & - & - & direct rating \\
\hline \multicolumn{7}{|c|}{ Human resource planning: } \\
\hline Tavana & 1996 & 13 & 7 & $\begin{array}{l}\text { individual and } \\
\text { group }\end{array}$ & 12 decision makers & pairwise comparisons \\
\hline Kwak & 1997 & 59 & - & individual & policy experts & pairwise comparisons \\
\hline Weingarten & 1997 & 3 & - & $\begin{array}{l}\text { individual and } \\
\text { group }\end{array}$ & hospital staff & pairwise comparisons \\
\hline Liao & 2009 & 12 & & individual & 48 hospital staff & Pairwise comparisons \\
\hline
\end{tabular}

In case of management decisions, 15 to 25 decision criteria are generally analyzed in a group of 15 or less experts, including health professionals, managers, patients or others.

Table 5. Governmental policy

\begin{tabular}{|c|c|c|c|c|c|c|}
\hline Author & Year & \# crit. & \# alt. & $\begin{array}{l}\text { Individual } \\
\text { or group }\end{array}$ & Participants & $\begin{array}{l}\text { Pairwise comparisons } \\
\text { or direct rating }\end{array}$ \\
\hline \multicolumn{7}{|c|}{ Resource allocation to healthcare programs: } \\
\hline Matsuda & 1998 & 6 & - & - & 53 citizens & pairwise comparisons \\
\hline Grof & 2007 & 5 & 6 & - & - & - \\
\hline Taneja & 2007 & - & - & - & - & - \\
\hline Shin & 2008 & 25 & 2 & individual & 88 experts & pairwise comparisons \\
\hline $\mathrm{Bi}$ & epub & 4 & 40 & - & - & pairwise comparisons \\
\hline \multicolumn{7}{|c|}{ Policy for new te chnology: } \\
\hline Cho & 2003 & 8 & 88 & group & $\begin{array}{l}8 \text { clinicians, } \\
4 \text { engineers }\end{array}$ & pairwise comparisons \\
\hline Nuijten & 2004 & 3 & 3 & individual & few experts & pairwise comparisons \\
\hline Smith & 2010 & 8 & 35 & individual & 4 experts & pairwise comparisons \\
\hline \multicolumn{7}{|c|}{ Societal norms: } \\
\hline Koch & 1998 & 19 & 3 & group & researchers & pairwise comparisons \\
\hline
\end{tabular}

In case of health care policy making, 10 to 15 decision criteria are generally analyzed either by a relatively large group of individual experts, or in a group session with 10 or less experts. The outcomes are intended to represent the general population, or a target group within this population.

\section{Conclusions and discussion about the past of the AHP}

From the review it is concluded that the AHP is increasingly being used in health care and provides valuable support in complex healthcare decisions. Most of the applications deal with complex decision structures. The most complex decision structures were found at the level of management in health organizations, and biomedical innovation. The evaluation of the effects of a new health intervention on the health care organization is often represented in complex decision structures. Technologies can be evaluated based on the costs, advantages and disadvantages for the groups involved. One appropriate application of the AHP involves group discussions between health professionals, managers, patients, or others. Likewise, the AHP can support the relatively complex decisions about technological innovations about which clinical evidence has not yet been gathered. In this case the technology can be assessed in a multidisciplinary group setting with technological developers with state-of-the-art knowledge about the new technology, and clinicians. For complex decisions about national health care policy, an alternative approach more often applied is to consult individual experts in a Delphi setting. 
The AHP is also frequently applied to support clinical experts to decide upon clinical guidelines and to implement shared decision making. Shared decision making is the process of informing patients and eliciting preferences for treatment. If preferences among patients vary widely, or the preferences of the patients are likely to differ from the preferences of physicians, the AHP is valuable in this context.

\section{Recommendations for the future of the AHP}

In general, we recommend the use of the AHP to support the assessment of health care technology in case of complex decision problems, a need to improve decision making in stead of explaining decision outcomes, a need to share information among experts or between clinicians and patients, and in case of a limited availability of informed respondents.

We foresee the increased use of the AHP in conducting comprehensive Health Technology Assessments. The literature review has shown that the AHP is a valuable tool to support decision making about new health technology. The, consensus based, group decision making process allows a multi-disciplinary team of experts to judge the relative importance of the outcome measures of new technologies attributes and to reach a conclusion about the overall benefit of the technology being evaluated. In this respect, its main advantage is that it allows discuss ions between panel members and, hence, the exchange of information.

More specifically, AHP can be used to support health economic evaluations of new health care technology. Although AHP has primarily been developed to support management decision making, it may have a role in (1) prioritizing multiple patient-related outcomes in clinical trials and (2) analyzing the net benefit of health interventions. By developing a hierarchical structure of the outcome measures considered, it is possible to determine weights for separate and for categories of patient-relevant endpoints. This could be done before the benefits assessment, preferentially in a large group of informed patients. However, up to now AHP has not often been used for this particular purpose and more research is warranted on the applicability of AHP in a survey and the difference with utility based patient-reported outcome measures.

\section{REFERENCES}

Dolan, J.G., \& Bordley, D.R. (1993). Involving patients in complex decisions about their care: an approach using the analytic hierarchy process. J Gen Intern Med, 8(4), 204-209.

Saaty, T.L. (1994). Highlights and critical points in the theory and application of the Analytic Hierarchy Process. European Journal of Operational Research, 74, 426-447.

Mulye, R. (1998). An empirical comparison of three variants of the AHP and two variants of Conjoint Analysis. Journal of Behavioral Decision Making, 11, 263-280.

Scholl, A., Manthey, L. Helm, R., \& Steiner M. (2005). Solving multiattribute design problems with analytic hierarchy process and conjoint analysis: an empirical comparison. European Journal of Operational Research, 164, 760-777.

Hummel, J.M., Rossum, W. van, Verkerke, GJ., et al. (2000). Assessing medical technologies in development. A new paradigm of medical technology assessment. Int J Technol Assess Health Care, 16(4), 1214-1219. 